$\$$ sciendo

\title{
Como é a Filosofia Analítica Possível?
}

\author{
Simon Blackburn \\ University of North Carolina, Chapel Hill
}

Disputatio No. 4

May 1998

DOI: $10.2478 /$ disp-1998-0001

ISSN: 0873-626X 


\title{
COMO É A FILOSOFIA ANALÍTICA POSSÍVEL?*
}

\author{
Simon Blackburn
}

I

Pouco antes do início do presente século, deu-se um episódio digno de nota em Viena. Em 1894, a Universidade encomendou a Gustav Klimt uma série de painéis que descrevessem o triunfo da luz sobre as trevas. O primeiro painel, concluído por Klimt em 1900, representava a Filosofia. Os Lentes esperavam, claro, qualquer coisa como a descrição rafaelina da escola de Atenas: Platão e Aristóteles, e talvez Galileu, Hume, Kant e Mach, dissertando gravemente perante uma multidão convenientemente impressionada que assistia e aprendia. Um tal painel confirmaria a natureza racional e esclarecedora da filosofia e celebraria o seu reconhecido papel social. Mas Klimt, fortemente influenciado por Schopenhauer, Wagner e Nietzsche, acabou por apresentar uma tenebrosa representação do Vazio no qual a humanidade turbulenta vagueia sob o jugo todo-poderoso da Paixão e da Vontade, não tendo o Conhecimento, representado por uma Esfinge de formas bastante vagas e por uma inflexível figura de Medusa, claramente nenhum efeito no resto dos trabalhos. O painel provocou um enorme tumulto, afirmando os Lentes, claro, que Klimt não sabia o que estava a fazer. A filosofia analítica estava prestes a acabar ainda antes de ter propriamente começado.

Passaram já mais de dez anos — dez anos que nos aproximaram do fim do século - desde que Richard Rorty publicou A Filosofia e o Espelho da Natureza, proclamando uma vez mais o fim da filosofia analítica. Se alguma coisa mudou nas correntes que Klimt, no princípio do século, e Rorty, já mais para o fim, identificaram como fundamentalmente hostis à imagem que

\footnotetext{
* Conferência proferida na SPF no 33. ${ }^{\circ}$ Encontro de Filosofia Analítica (19 de Maio de 1997), por ocasião do lançamento da edição portuguesa do Dicionário de Filosofia (Gradiva, 1997). Publicado originalmente na revista Canadian Journal of Philosophy Supplementary Volume 19 (1993).
}

\section{Disputatio 4 (1998)}


essa disciplina tem de si mesma, foi no sentido de se tornarem mais fortes. É quase impossível ver como pode praticar-se filosofia analítica em boa consciência.

Começarei por apresentar a minha própria sinopse do caso em disputa, deixando de lado quase certamente tantas críticas tão importantes quantas as que incluí; mas isso será suficiente, espero, para avançarmos. Muito do que irei dizer já é conhecido, mas acrescentarei algumas dúvidas menos familiares acerca do método contemporâneo nas secções seguintes, nas quais levanto dúvidas acerca de uma das indústrias contemporâneas mais populares — a «naturalização» de áreas como a moral ou a semântica, conseguida à custa da identificação das propriedades em causa com as propriedades de certa classe favorecida. Por fim, esboçarei uma resolução. Mas comecemos pela acusação.

1.

Não há uma filosofia primeira. Que quer isto dizer? Muitas pessoas diriam que Quine mostrou que o a priori não existe e que uma filosofia primeira precisa de princípios a priori; logo não pode existir nenhuma filosofia primeira. Mas esta conclusão não precisa de uma premissa assim tão controversa. Quine não mostrou que o a priori não existe (os que pensam que ele fez literalmente isso mesmo têm de verificar o conceito de demonstração que possuem, para que a sua posição não se autodesconstrua de forma exemplarmente rápida). A analiticidade continua a ser claramente atribuível a muitas equivalências lexicográficas; a definição é um processo em aberto. ${ }^{1}$ Na melhor das hipóteses, Quine mostrou algo muito mais fraco: talvez que nenhuns princípios suficientemente substanciais para gerar um método filosófico poderão ser a priori. Mesmo que frases como «os solteiros não são casados» e outras semelhantes escapem à sua crítica, não servem para construir um método; envolvem unicamente conceitos superficiais, ou conceitos em relação aos quais as definições de dicionário constituem uma identificação crucial. Qualquer filosofia que procure dar uma posição «primeira», ou uma perspectiva exterior de uma ou outra área de discurso, precisa de muitas mais coisas substanciais e nada de mais substancial será conseguido a priori pelas ligações superficiais exploradas nos dicionários. Uma filosofia primei-

\footnotetext{
${ }^{1}$ Strawson \& Grice, «In Defence of a Dogma», Philosophical Review (1956).
} 
ra explorará categorias (verdade, existência, descrição, facto, agência, conhecimento, etc.) cujas identidades terão determinadas raízes, serão históricas, contingentes, situadas e sujeitas ao julgamento e à substituição, em função da sua utilidade na prática. Não podemos vê-las como se mantivessem uma exigência sobre o pensamento que fosse intemporal e à prova de culturas. No caso mais favorável possível, quando um conceito substancial é introduzido explicitamente em certos termos, sujeita-se a tornar-se órfão, se percebermos que dar-lhe uma vida própria acaba por funcionar bem. Ainda que Quine nos tenha tornado receptivos apenas a isto, é mesmo assim suficiente para debilitar a filosofia primeira. E se a filosofia primeira é o único conceito de filosofia que temos, podemos apagar a palavra «primeira» da frase anterior.

2.

Não existe um ponto de Arquimedes, nem uma perspectiva lateral, nem uma doca seca, a partir da qual possamos inspeccionar o progresso do nosso próprio barco científico ou valorativo, ou o de qualquer outra actividade intelectual. As práticas assentam nos seus próprios pés. Não podemos por isso dar realmente sentido ao juízo que afirma que o nosso barco se está a sair bem ou mal, que vai em direcção à verdade ou que se afasta dela. Não há nada, no fim de todas as investigações, que esteja destinado a reunir consenso, porque novas circunstâncias produzirão novas questões, novas práticas e novas técnicas de aproximação. Claro que pensamos que os nossos juízos são verdadeiros, ou quase, mas isto é porque são nossos; e dizer que são verdadeiros não é mais do que uma maneira opcional de os fazer.

3.

Não há, por isso, Guardiães das Normas. A filosofia primeira não só aspirava a um ponto de vista externo em relação aos discursos, mas também a um ponto de vista que tivesse autoridade normativa. Um ponto de vista que revelaria e defenderia uma lógica comum no método científico e que arbitraria as actividades intelectuais a partir das suas regras. Mas, mesmo que não o tivéssemos já aprendido com Hume, teríamos já aprendido, a partir do fracasso das teorias normativas da justificação e da confirmação e a partir de Goodman, de Kuhn, de Feyerabend e dos seus sucessores, que não existe um 
ponto de vista normativo externo e privilegiado acerca de uma disciplina intelectual. A «racionalidade» é em primeiro lugar uma palavra polémica e, em segundo lugar, retrospectiva. Os sobreviventes da luta darwinista orgulham-se da sua capacidade de adaptação e os sobreviventes científicos ou intelectuais da sua luta darwinista, na qual as teorias são concebidas e ou morrem ou sobrevivem, orgulham-se da sua racionalidade. Mas uma consideração séria da situação histórica a partir da qual as teorias e as ideologias emergem não mostra nenhuma assimetria de racionalidade, mais visível a partir de uma perspectiva privilegiada e filosófica. Claro que os cientistas e ideólogos individuais, assim como os seus seguidores, podem exibir, por vezes, o seu quinhão de fragilidade humana: terão sido casmurros, excessivamente confiantes, tacanhos, descuidados e ter-se-ão enredado em projectos absurdos, como toda a gente. Mas estes juízos fazem-se melhor na caverna de primeira ordem do urso, onde tem lugar a luta pela sobrevivência. A caverna do urso não reconhece quaisquer árbitros durante a prova e quando esta chega ao fim os historiadores estão numa posição muito melhor do que os filósofos para descrever com o detalhe necessário e lúcido os estilos exibidos pelos vários concorrentes. Efectivamente, é especialmente improvável que um filósofo possa entrar pela ciência adentro e distribuir prémios de racionalidade. Mesmo na improvável eventualidade de ele ser melhor do que qualquer outra pessoa a identificar a casmurrice e tudo o resto, não é provável que estes traços sejam vulgarmente visíveis ou mesmo particularmente comuns na vanguarda da investigação. A luta darwinista por uma voz na disciplina de primeira ordem já os terá exterminado. ${ }^{2}$

Por causa disto não há epistemologia normativa, nem nenhuma filosofia da ciência que possa desempenhar o seu papel tradicional. Há a ciência e há a história da ciência, nenhuma das quais poderá ser executada especialmente bem por pessoas com prática noutras áreas, como na filosofia. Também podemos constituir uma claque de apoio à nossa equipa, assegurando que uma certa ciência está a sair-se bem. Uma vez que os padrões do que é sair-se bem, nesta maneira de ver as coisas, são estabelecidos pelos próprios cientistas, esta não é uma ocupação particularmente nobre.

\footnotetext{
${ }^{2}$ Isto não tem de ser assim no que respeita a outras actividades: os militares, por exemplo, têm a tendência de promover as pessoas precisamente por causa destes e outros defeitos. Veja-se Norman Dixon, On the Psychology of Military Incompetence (Londres: Jonathan Cape, 1976).
} 
4.

Não há maneira de nos livrarmos da diversidade. A ética não é crítica literária nem história, biologia, física ou psicologia - e nenhuma destas é a mesma actividade do que qualquer das outras. É de esperar o pluralismo porque há tantos tipos bons de descrições de coisas quantos os propósitos ao descrevê-las. A perspectiva do físico não é a mesma que a do historiador ou do biólogo - mas, afinal, a perspectiva que se tem da Torre Eifell quando a vemos de Montmartre é diferente da que se tem a partir do Invalides. Acreditar numa redução é exactamente como procurar alcançar uma perspectiva da Torre Eifell a partir de Montmartre que seja a partir do Invalides - como se pensássemos: o Invalides oferece-nos em geral uma perspectiva mais próxima e melhor; portanto, por que razão não poderá a perspectiva de Montmartre ser visível a partir dela?

5 .

Porque não podemos negar a diversidade, porque não há redução nem epistemologia, também não há ontologia. Mesmo Quine vacilou neste aspecto - e a sua timidez é ilustrativa. Quine pensou (ou escreveu como se o pensasse) que uma afirmação existencial presente numa ciência fazia duas coisas. Dizia qualquer coisa de primeira ordem que precisava de dizer e, se a deixássemos sozinha, exprimia uma outra coisa, sinistra, um «compromisso ontológico» ou ónus filosófico, uma causa de preocupação e dificuldade para pensadores sérios com consciências ônticas delicadas.

Mas isto é contar a mesma coisa duas vezes. «Existe um número entre o seis e o oito» diz uma só coisa - que qualquer criança da terceira classe compreende e aceita. «Num átomo neutro existe o mesmo número de protões e electrões» é uma tese elementar de química física. Estas frases não exprimem também um compromisso «ontológico» filosoficamente oneroso. Pensar que o fazem é ansiar por uma redução, ou acreditar que alguém que não um matemático ou um físico, como um Guardião das Normas, tem algo a dizer acerca delas (que são inaceitáveis por atravancar a sua paisagem deserta, por exemplo). Mas os pontos 1, 2 e 3 mostram que isto é uma fantasia. Uma preferência por paisagens desertas não pode ser diagnosticada como uma postura filosófica - na melhor das hipóteses será uma postura política. Equivale a desejar privilegiar um certo discurso com cujas quantificações 
nos sentimos particularmente confortáveis. Qualquer pessoa pode ter um tal desejo, ou o seu oposto, mas não unicamente por motivos racionais - e, sobretudo, não o tem por ter olhos especialmente bons para detectar perigos ontológicos escondidos, invisíveis para a física ou para a matemática.

Não acontecerá antes isso porque conquistaram uma função judiciosa especial, que lhes permite avaliar de forma independente tal discurso, não tanto em termos de verdade, mas como escolhas de quadros de referência e coisas semelhantes? Só a prática pode determinar se a escolha de uma linguagem matemática, física, psicológica, modal, moral ou religiosa é vantajosa para nós. O filósofo pode, como um amador com sorte, contribuir para o reconhecimento da excelência ou debilidade de um discurso qualquer, mas não existe uma profissão que consista em ter sorte. E quando um discurso ou uma forma de vida morre, como aconteceu efectivamente com a forma de vida religiosa no Ocidente, tal nunca acontece por não resistir ao escrutínio de Minerva, mas porque as consolações e as promessas que oferece acabaram por perder o poder de nos animar. A única coisa que o filósofo pode fazer é conduzir o carro funerário, proclamando que sabia antes das outras pessoas que o paciente estava morto.

O que tem a tendência de passar por ontologia é apenas um exercício de «guarda-livros» - ensaios sobre a adequação expressiva de uma maneira ou outra de dizer coisas. ${ }^{3}$

6.

Por razões análogas, não sobra um assunto especial nas ciências intencionais ou na teoria do significado, tal como esta tem sido entendida na tradição. O colapso da epistemologia ensina-nos a não achar o conhecimento da psicologia particularmente misterioso. O colapso do reducionismo leva-nos a perceber que existem muitas maneiras de descrever os seres humanos, constituindo os idiomas intencionais uma delas.

A quantidade de trabalho produzido na intersecção entre a ciência cognitiva e a filosofia da mente pode parecer refutar esta conclusão fácil. Mas uma inspecção mais cuidadosa sugere que ou este trabalho não é propriamente filosófico (por exemplo, o trabalho de pessoas como Marr ou o dos

\footnotetext{
${ }^{3}$ Devo o termo a Mark Johnston, «Objectivity Refigured», Realism and Reason, J. Haldane \& C. Wright, orgs. (Oxford: Oxford University Press, 1992).
} 
conexionistas), ou que, quando o é, é escravo dos mesmíssimos preconceitos e ambições de primeira ordem que esta crítica mostra não terem bases (por exemplo, ao depender de concepções ingénuas de redução, ou de caracterizações ingénuas do que um facto natural tem de ser, ou do «realismo»). Efectivamente, se a filosofia influenciou a prática da ciência cognitiva, exceptuando os casos em que se constituiu como claque de apoio, é de recear que o tenha feito sobretudo negativamente, uma vez que a contribuição que introduz na conversa é possivelmente uma insistência inoportuna em distinções e perspectivas sem crédito. Precisam os cientistas cognitivos dos honestos serviçais e criadas de Locke? Por que haviam de precisar, se têm máquinas para isso? A criada filosófica é muito provavelmente o tipo de pessoa que poderia ter segredado a Alexander Graham Bell que o telefone era um sonho contraditório, porque falar com alguém requer conceptualmente que se esteja na sua presença. O melhor que o aliado filosófico da ciência cognitiva pode provavelmente fazer é oferecer protecção mafiosa, intimidando os jogadores com a sugestão de que sem os seus serviços os outros filósofos virão estragar o jogo todo.

Se, nesta área, há moscas na garrafa das moscas, tal filosofia não é adequada para lhes mostrar a saída; a via da sabedoria será esperar que o progresso científico dissolva toda a garrafa, juntamente com os insectos que a povoam. ${ }^{4}$

7.

Não há uma Ciência Fregeana do Sentido. Uma Ciência Fregeana do Sentido exige que determinadas proposições objectivas tenham relações lógicas específicas, de maneira a que os Guardiães das Normas possam perseguir os pensadores marginais que transgridam essas relações. Mas Wittgenstein, Collingwood e outros autores mostram-nos que o conteúdo tem de ser naturalizado. É uma depuração do uso que as pessoas fazem das suas frases e sobretudo das inferências que acham natural fazer. Logo, não há um ponto de vista a partir do qual a lógica possa ditar uma ampla satisfação com o status quo, nem uma sua ampla revisão. Podemos intentar acções de saque limitadas ou locais contra certos vícios, como acontece na Introdução ao

\footnotetext{
${ }^{4}$ Este argumento encontra uma expressão enérgica em Stephen Stich, «What is a Theory of Mental Representation?» in Mind 101 (1992).
} 
Pensamento Crítico, mas isso dificilmente é suficiente para sustentar uma vida intelectual.

Quanto ao projecto de fundar qualquer coisa chamada metafísica em qualquer coisa chamada lógica, trata-se sempre de um disfarce para um qualquer tipo de investigação epistemológica sobre a aprendizagem ou transmissão da linguagem - investigação que herda, enquanto tal, todos os defeitos da epistemologia normativa e que tem, muitas vezes, alguns defeitos próprios, como quando se trata da epistemologia da moda (o verificacionismo ou uma crença ingénua na transparência dos factos em relação às mentes em circunstâncias favoráveis), exibida confiantemente como o fundamento «lógico» incontroverso da restante filosofia. ${ }^{5}$

8.

Não há nenhuma teoria ética. Seria necessário mais do que alguns comentários gerais para fazer abalar os últimos bastiões dos Guardiães das Normas. Mas eu irei sugerir como poderíamos abalá-los, porque isso nos permitirá tirar uma lição geral em relação à prática da filosofia. Suponhamos que uma teoria ética ou política aspiraria a duas coisas: simplificaria e explicaria a aparente complexidade dos juízos éticos ou políticos quotidianos; e ganharia, assim, autoridade didáctica ditando, ou pelo menos certificando, veredictos em casos novos e em casos sob disputa. Mas então temos de reconhecer que as melhores descrições do que é a ética e de como ela é efectivamente conduzida sugerem fortemente que não há, de facto, lugar para tal teoria. Estas descrições dão-nos uma ideia dos dilemas e das considerações rivais que frequentemente nos confundem. A resposta filosófica é inventar um processo de alcançar um «equilíbrio reflexivo», no qual o peso certo dessas considerações emergirá de uma maneira ou de outra, «resolvendo» de uma maneira ou de outra os dilemas. Mas o que se descreve em termos optimistas como um equilíbrio reflexivo, como se um equilíbrio estável e eivado de autoridade tivesse sido alcançado, é efectivamente muito mais uma questão de ficar emperrado. É descobrir que considerações rivais e em conflito se limitam a encravar, de maneira que a resolução a tomar terá de se al-

\footnotetext{
${ }^{5}$ Para um excelente diagnóstico desta tendência, veja-se Edward Craig, «Advice to Philosophers: Three New Leaves to Turn Over», Proceedings of the British Academy 76 (1991), pp. 265-281.
} 
cançar muito mais através da escolha arbitrária de uma ou outra alternativa do que através da operação de um processo de raciocínio.

Mas suponha, ao invés, que emergiu realmente uma sistematização que seja a que melhor se conforma e a que de algum modo explique intuições existentes. Como é exactamente que isso deverá conferir-lhe autoridade didáctica? As intuições existentes são as convicções irreflectidas de um tipo específico de animal, com uma experiência, história e enquadramento cultural (muito) específicos. Tal enquadramento incluirá em grande parte o contágio de atitudes, emoções e crenças de outros familiares, mentores e pares imperfeitos, operando em circunstâncias nas quais algumas formas de vida funcionam e outras não, e nas quais algumas atitudes estavam na moda e outras eram demasiado caras para serem funcionais. A «teoria» implícita ou tácita que melhor sistematiza a selva de atitudes gerada por um tal processo não merece mais respeito do que as próprias atitudes; uma vez que tudo o que pode ser dito sobre elas é que emergiram num dado momento sob outras circunstâncias e que sobreviveram até agora, então isso pode não ser grande coisa.

Isto vê-se claramente se imaginarmos uma empresa análoga conduzida pelos que têm, numa outra esfera, atitudes visivelmente mergulhadas nas trevas da ignorância. Imagine um grupo de novos-ricos do nível estético que os faz ter carpetes com flores, loiças de quarto de banho cor-de-rosa e ornamentos patéticos. Suponha que este grupo começa a sistematizar os processos que conduzem ao equilíbrio reflexivo estético. Por mais que achem que os princípios daí resultantes são intuitivos, centrais e até mesmo úteis («as coisas que dão aconchego são mais bonitas do que as que não o dão»), o exercício é completamente fútil quer porque está a inventar um sistema em vez de o descobrir, quer porque não é previsível que haja qualquer hipótese de o sistema inventado melhorar as suas faculdades de ajuizar em novas ocasiões. Poderia fazê-lo - mas isso seria por acaso. Sistematizar um equilíbrio estético seria um exercício de racionalização de um status quo que não precisa de ser racionalizado mas antes diagnosticado e, no caso que descrevi, abandonado.

Mas, em qualquer caso, é uma ilusão esperar que emirja uma teoria que melhor justifique as intuições actuais e os guias dos casos futuros. Chegamos a essas intuições não através de um exercício sincrónico de selecção e avaliação, mas através de uma evolução histórica: as teorias que os participantes anteriores nessa história poderiam ter usado para justificar as suas 
intuições a si mesmos são, muito provavelmente, virtualmente ininteligíveis para nós e não há razão para imaginar uma síntese única que abranja todos os sedimentos heterogéneos. Quando vemos como os pontos foram dispostos vemos também que não há razão para esperar que exista uma curva que melhor se lhes adapte, nem para seguir qualquer uma delas em direcção a novas regiões. Seria como redigir as equações geométricas que melhor se adaptam à forma de uma árvore e acreditar que encontrámos um princípio que subjaz ao seu desenvolvimento.

Uma teoria ética, no sentido em causa, exige a crença de que a selva de pressões, às quais a tomada de decisões responde, revela uma estrutura oculta - uma ordem teórica oculta - à espera do filósofo que irá revelar um sistema oculto, que contenha uma autoridade normativa oculta. Mas uma compreensão realista (histórica e cultural) da razão pela qual os elementos da mistura existem sugere que não é provável que se encontre nenhum elemento individualmente (porquê um sistema? Porquê a autoridade, quando reflectimos sobre o modo como a obtivemos?) e é quase impossível que os encontremos juntos. Há um racionalismo implícito na procura da teoria, como se a inteligência comum da humanidade tivesse ditado (em lugar de Deus) uma ordem oculta nos vários sedimentos, cuja natureza e desenvolvimento o iniciado pudesse ter o privilégio de desvendar. Mas não há razão para acreditar nisto no caso dos sedimentos intelectuais e morais das águas constantemente renovadas da necessidade e da história culturais. A crença de que há uma tal ordem é surpreendentemente análoga à confiança no Argumento do Desígnio: uma vez que há complexidade, tem de haver uma arquitectura inteligível, cujos planos possam ser desvendados através de suficiente pensamento. Não há razão para acreditar nisso e, mesmo que substituamos a Evolução pelo Desígnio, assumindo uma confiança do tipo da de Burke na sabedoria herdada dos tempos, continua a não haver razão para acreditar nisso. É improvável que o que evoluiu seja uma capacidade magistral para pensar nos problemas da vida de modo coerente e sujeito a princípios; será antes uma série de «kludges» ou respostas parciais e ad hoc a pressões que, na melhor das hipóteses, fizeram com que os nossos genes tenham sido úteis em algumas circunstâncias restritas. Procurar a teoria torna-se uma espécie de numerologia, como procurar códigos ocultos nos sonetos de Shakespeare, ou como procurar uma geometria racional numa árvore, ou um significado racional no modo preciso como os seixos estão dispostos num aglomerado geológico. 
Não haverá, portanto, nenhuma teoria ética ou política. Em seu lugar, haverá lugar para a advocacia prática e para o apoio activo a várias formas de vida. Podemos entregar-nos à filosofia «fácil e óbvia» que consiste em «pintar [um certo objecto] com as cores mais favoráveis», de modo a «ser agradável à imaginação e a prender as emoções». ${ }^{6}$ Não se trata de afirmar que não devia haver pessoas a fazer isto, mas antes que elas deviam reconhecer que isto é tudo o que estão a fazer. Deviam vestir o hábito do evangelista e não o da Academia.

II

Apresentei o caso em traços gerais e sinistros; a resposta pode parecer relativamente simples. No fundo, sabemos que a filosofia analítica continua a existir de uma maneira ou de outra - e por vezes de maneira admirável. Uma vez que ab esse ad posse, qualquer argumento que procure mostrar que ela não pode existir tem de ser deficiente. Mas onde está a deficiência?

Eis um tipo de resposta que penso ser apelativa para variadíssimos filósofos. ${ }^{7}$ Regressemos a Quine. As nossas reacções podem passar por três fases. Em primeiro lugar, há o instinto básico de que Quine não pode ter razão, uma vez que a definição, a abreviação e a introdução de termos cuja única ligação seja através de uma equivalência de dicionário parecem constituir características perfeitamente reconhecíveis da linguagem natural. Em segundo lugar, há a reflexão de que esses termos não ajudam muito a definir um método, uma vez que não há definições incontroversas de dicionário que forneçam nem mesmo os primeiros passos de soluções dos Grandes Problemas Filosóficos. Assim, em terceiro lugar, podemos deitar mão à tábua de salvação optimista, segundo a qual estes problemas substantivos e filosoficamente perenes podem estar escondidos, sob a superfície lexicográfica, em conceitos que têm ligações teóricas que merecem efectivamente um estatuto a priori análogo. Devia haver espaço para uma ciência — a que poderíamos chamar ciência de Oxford - do que é constitutivo de tais conceitos. Uma

\footnotetext{
${ }^{6}$ David Hume, Investigação Sobre os Princípios do Entendimento Humano, Secção I.

Tive o prazer de encontrar uma excelente formulação da posição no artigo de Elizabeth Fricker, «Analyticity, Linguistic Practice, and Philosophical Method» in Meaning Scepticism, Klaus Puhl, org. (Nova Iorque: De Gruyter, 1991).
} 
ciência a priori do conhecimento, da verdade e do resto revelaria as ligações teóricas ocultas - ligações às quais estes conceitos respondem.

Por que razão descrevo isto como o deitar mão a uma tábua de salvação optimista? Porque não consegue identificar a verdadeira razão pela qual as ligações triviais e superficiais funcionam como $a$ priori. Não consegue ver que o seu estatuto enquanto refutação de Quine depende inteiramente do facto de as equivalências estarem à superfície, de serem unidimensionais e de serem essenciais ao processo de ensino. É tentador pensar que, uma vez que há analiticidades como estas, poderá haver também analiticidades teóricas ocultas. Mas isto não será assim se a postura peculiar do analítico depender de o facto que mantém um conceito no seu lugar ser a sua única ligação lexicográfica com uma definição. ${ }^{8}$ Qualquer outra coisa que seja menos óbvia e mais teórica não conseguirá alcançar o estatuto. ${ }^{9}$

Suspeito que a resistência a este aspecto resulta parcialmente de confundir a real complexidade introduzida quando vemos os conceitos como sendo «mantidos no seu lugar» por uma rede ou teia de ligações teóricas, em vez de o serem por um conjunto de listagens de condições necessárias e suficientes. Admitida esta imagem, haverá sempre o perigo de um pedido especial para elevar qualquer uma das ligações teóricas a algo «a priori» ou «constitutivo do conceito». Basta relembrar o estatuto «a priori» de princípios teóricos como a luz se deslocar em linha recta, a massa ser igual independentemente das propriedades dinâmicas de um corpo, o carácter infinito do espaço, etc., para nos darmos conta do perigo. Para uma genuína ciência de Oxford seria necessário não apenas

(a) a identificação de uma ligação teórica como essencial ao nosso conceito,

\footnotetext{
${ }^{8}$ Não estou aqui a sugerir que o carácter óbvio é de algum modo suficiente para um veredicto «popular» de «analítico». Mas pode ser necessário. Veja-se «Morals and Modals» no meu Essays in Quasi-realism (Nova Iorque: Oxford University Press, 1993).

${ }^{9}$ Jonathan Bennett defendeu a prática da metafísica strawsoneana como a repetição de passos óbvios em direcção a conclusões nada óbvias, por exemplo no seu Kant's Analytic (Cambridge: Cambridge University Press, 1966). Não pretendo refutar aqui a possibilidade teórica, mas há qualquer coisa parecido com o Sorites em todos os casos que conheço. Tal como num Sorites, fora dos contextos matemáticos e formais há uma tendência para que não seja nada óbvio que possamos acumular todos os passos óbvios.
} 


\section{mas também}

(b) razões pelas quais o nosso conceito tem de ser $o$ conceito que permite que uma certa categoria geral de pensamento funcione.

E a dificuldade será a seguinte: seja o que for que tenha a tendência de tornar (a) fácil terá a tendência de tornar (b) difícil. Expliquemo-nos: se nos convencermos a nós mesmos de um qualquer caso de (a), a tendência será fazê-lo explorando o que diríamos perante casos reais e possíveis; quanto mais nos apoiarmos neste método, menos conseguiremos ter em vista a impropriedade de um conceito substituto e de um modo de caracterizar coisas que abandona a ligação particular e privilegia uma outra. Acho que é por isto que o sintético a priori kantiano é muito mais importante do que discussões recentes que procedem deste modo. Kant percebe claramente que precisamos igualmente de (a) e de (b). De outro modo, a metafísica descritiva não será realmente metafísica - será apenas descritiva.

Como um primeiro exemplo simples, considere-se a indústria do debate sobre a questão de saber se uma perspectiva moral ultrapassa necessariamente as considerações não morais; suponha-se que decidimos que ultrapassa porque pensamos que naturalmente não diríamos («acharíamos que seria contra-intuitivo dizer») que alguém tinha genuinamente uma perspectiva moral caso essa pessoa permitisse que as considerações morais a ultrapassassem. E então? Mudemos o peso que damos a essa característica. Se se objectar que isso seria mudar o conceito, Quine responderá acertadamente que não temos nenhuma condição de identidade anterior, associada ao conceito, que faça com que seja obrigatório, ou mesmo útil, dizer isso a menos que possa mostrar-se que o novo conceito não poderia ter um papel essencial qualquer, de modo que o pensamento prático entraria de algum modo em colapso na sua presença. Neste exemplo, há poucas ou nenhumas perspectivas de o fazer, uma vez que as outras ligações teóricas do moral carregarão com o fardo. Que acontece de errado quando descrevemos alegremente algumas pessoas como possuindo uma moralidade que elas por vezes transgridem deliberadamente?

Para um exemplo mais interessante, considere-se a indústria da referência. Quando nos referimos nós a uma coisa? Entre os elementos aos quais as nossas intuições respondem contam-se 
— Relações causais e históricas

- Capacidade de descrever

- Capacidade de identificar (não é a mesma coisa)

- Pertença a uma comunidade com qualquer dos elementos supra

- Poder ser tomado como tendo falado de

- Ser caridosamente interpretado como tendo falado de

— Ter a disposição de se comportar de formas associadas relativamente a

e sem dúvida muitas mais (esta lista só demorou um par de minutos a formular). Em cada categoria há, sem dúvida, subcategorias potencialmente importantes. Qual é a verdadeira referência? Será que o povo se importa? Quase certamente que não: quando uma ou duas destas estão presentes, as outras habitualmente também o estão. Será que uma «teoria popular» ou implícita nos dá uma ordem com as propriedades atribuídas à teoria moral supra - oferecendo uma sistematização das nossas intuições e ditando veredictos relativamente a novos casos? Provavelmente não; por que precisámos afinal de desenvolver uma tal teoria? A referência é um termo factivo e em casos primitivos a factividade é normalmente sobredeterminada pelas amplas relações que temos com as coisas de que nos dispomos a falar. Por que razão deveria o povo ter pensado seriamente sobre as dimensões do insucesso e sobre o quanto se importa com isso à medida que os casos se tornam mais exóticos? Como poderia ele ter-se tacitamente apropriado antecipadamente das engenhosas experiências mentais dos filósofos mais recentes, que têm o ócio que lhes permite desenlear os fios da teia um a um, de modo a determinar se os outros fios suportam a pressão? Uma vez mais vemos o racionalismo implícito, como se o ponto de vista popular, sintetizado ao longo das eras, não nos deixasse um agregado de sedimentos para nós nos apoderarmos conforme pudermos à medida que formos construindo, mas um granito pré-formado e previamente amalgamado.

Serão os filósofos especialmente bons relativamente a (b), isto é estarão treinados para prever o colapso de um modo de pensar quando uma ligação teórica favorita de um conceito profundo perde o privilégio que lhe foi atribuído, seja ele qual for? A lição de Kant não é encorajadora. Repare-se como teria sido fácil esperar que o pensamento mecânico formulado em termos de massa entrasse em colapso dado que a massa em repouso e a massa em aceleração podem ser diferentes, ou como é fácil esperar que o pensamento geométrico entre em colapso caso se permita que a luz descreva um percurso curvo, ou caso se permita que o espaço tenha fronteiras. Que filósofo teria dito antes da ciência matemática que um número poderia ser outra coisa para além do 0 e de um dos seus sucessores? Suponha agora que damos voltas no 
nosso espírito às verdades a priori constitutivas exibidas como conceitos difíceis: por exemplo, a de que quem tem crenças tem de ter principalmente crenças verdadeiras, ou a de que as crenças causam acções. Tudo o que parece que somos capazes de fazer é registar um anexo a essas verdades, talvez porque se descobre que algumas possibilidades de contra-exemplos estão bloqueadas. Mas como poderemos nós alguma vez prever as vantagens que poderiam decorrer de aprender a pensar de forma ligeiramente diferente (e, claro, virando as costas à questão de saber se teremos então um «novo» conceito)? Como poderemos sustentar que uma mudança que torne essa via natural seria mais revolucionária e reformadora do que a falência da massa newtoniana ou a introdução dos números racionais, dos reais, etc., na matemática? Como poderemos delimitar os modos como o caleidoscópio se pode agitar?

\section{III}

Veremos que o pessimismo da secção I não é suavizado pelas tentativas conservadoras da secção II. O problema, segundo me parece, é duplo. Em primeiro lugar, a analogia geológica sugere que é demasiado benevolente descrever-nos como possuindo uma teoria popular, ao invés de um conjunto de paradigmas ou estereótipos herdados, ou coisas para dizer sem que se vislumbre a possibilidade de possuírem estrutura e forma didáctica. Supor que as têm implica uma espécie de racionalismo, conferindo ao povo os atributos tradicionais de Deus, e imaginando que, diacronicamente, o povo terá resolvido as coisas à luz da razão à medida que avançava. Em segundo lugar, mesmo que superemos este obstáculo e encontremos uma verdadeira teoria, o seu direito a ser $a$ teoria terá de ser estabelecido, se queremos privilegiar qualquer dos seus elementos como constitutivos de uma noção de que precisamos, de um modo qualquer que seja interessante.

Há uma maneira de pensar acerca destas coisas, derivada de Ramsey e popularizada por David Lewis, que pode parecer rebater este diagnóstico. Nessa abordagem aos termos teóricos as «banalidades» que governam o uso de um termo são registadas, acabando por constituir uma lista de coisas tidas como verdadeiras acerca daquilo que o termo refere; o que o termo refere é então seja o que for que melhor se lhe adapte, satisfazendo a maior parte das coisas que dele se afirmam, se algo as satisfaz. Se as banalidades incluem casos vagos e casos indiferentes, será um aspecto a favor de um candidato se as mesmas coisas são vagas ou nada importantes quando pensamos acerca dele próprio. A grande vantagem de pensar deste modo é que não importa se as doutrinas iniciais se revelam razoavelmente difusas ou sem nenhuma or- 
dem hierárquica. Não tem de haver uma imputação de ordem ou precisão. Logo, se, como tenho vindo a defender, o povo é susceptível de nos ter deixado uma trapalhada, isso não é um problema: registe os elementos da trapalhada e o processo de fazer a melhor identificação irá impor a ordem suficiente para os propósitos filosóficos - por exemplo, para o propósito de explicar o uso original do termo, ou para tornar claro o modo de pensar nos novos casos, ou os veredictos a defender relativamente aos casos disputados.

Chamemos «classe doméstica» a uma classe de entidades, propriedades ou relações que acreditamos conhecer bem. Chame-se «classe exótica» à classe contrastante, que está a levantar problemas filosóficos. Então, o método de Ramsey-Lewis é ideal para fazer uma identificação exótico-doméstico. Pode parecer que a teoria cujas banalidades estão perante nós identifica uma coisa ou propriedade exótica (e.g., uma coisa não física, como um qualia ou uma propriedade moral ou semântica). Mas se encontrarmos uma coincidência suficiente entre as coisas que se dizem desta entidade ou propriedade e uma entidade ou propriedade doméstica, esta última entra em cena e a exótica é banida. Os qualia serão tais e tais acontecimentos físicos no cérebro; a referência será tais e tais relações naturais; as propriedades morais serão tais e tais propriedades naturais. Apesar do grande prestígio desta metodologia, confesso ser céptico quanto aos seus alegados sucessos, quando a propriedade em questão não é identificada cientificamente, mas antes através da herança popular. ${ }^{10}$ Em primeiro lugar, e o mais importante, depende de uma atitude inicial relativamente aos elementos da trapalhada. Se tivermos em vista a equação entre referência e relação causal-histórica, diminuiremos a importância de alguns elementos da trapalhada popular; se gostamos da ideia de referir os que estão por vir (como se diz que os profetas fazem, por exemplo) diminuiremos a importância de outros. A identificação de Ramsey parece muito menos capaz de resolver estas disputas, se ela própria for o resultado de uma ou outra atitude relativamente a elas. Pondo as coisas de outro modo: por que havia o povo de nos ouvir se tomamos a sua mistura, deitamos borda fora pedaços suficientes para fazer uma identificação doméstica e depois the dizemos que esse pedaços estavam errados? O método pressupõe que a um certo nível o povo se referia a uma propriedade doméstica. Por que razão o faria, sobretudo se nem ele nem os seus filósofos domesticados têm dificuldades em dizer de que propriedade se trata? Uma resposta é a do ontólogo: as coisas e as propriedades domésticas são as

\footnotetext{
${ }^{10}$ Passarei a falar apenas de propriedades, para evitar repetições, mas penso que as observações se aplicam às demandas filosóficas pela identidade dos estados, acontecimentos, coisas e até mesmo tipos.
} 
únicas que existem. Mas já defendemos que a ontologia é coisa que não existe. E talvez o predicado «popular» não esteja lá de maneira nenhuma para referir uma propriedade, se há tão poucas. (Mas o povo pensa que diz coisas verdadeiras, e só se um predicado referir uma propriedade é que uma frase que o contenha será susceptível de ser verdadeira. Por que razão acreditaremos nesta última coisa, se as propriedades são mais do que sombras semânticas dos predicados, e têm o seu próprio estatuto metafísico, dividindo-se em domésticas e exóticas, por exemplo? Não se trata de um axioma de uma teoria popular sobre a referência dos predicados.)

Suponha que o teórico da identificação pode passar ao lado destas questões. Não obstante, terá de confessar um problema residual. A compra da identidade tem custos fregeanos. Suponha que a referência é uma relação causal histórica, que as propriedades morais são naturais, ou que os qualia são estados do cérebro. Mesmo assim, há algo de especial acerca de ver uma relação causal histórica como uma relação de referência, ver uma propriedade moral como uma relação natural (ou como um agregado ou função de Boole de relações naturais), ou ter experiência de um estado do cérebro como um qualia. Não está certamente garantido que sempre que vemos a propriedade doméstica ou pensamos sobre ela a vemos ou pensamos sobre ela a uma luz semântica, moral ou consciente. Qual é a vantagem especial daquela propriedade trazida por aqueles que a vêm a essa luz? A única resposta não contaminada é esta: eles trazem a luz que os faz dizer estas coisas; e depois segue-se uma repetição das coisas que o povo diz; e isso deu origem à procura de uma identidade.

Ora, penso que há algo de errado na direcção tomada ao investigar-se tanto a questão da identidade, se temos de acrescentar à história uma teoria da vantagem especial. É um pouco como identificar odores com moléculas e sons com o seu movimento, mas admitir que a percepção de uma molécula como um odor, ou do movimento de várias delas como um som exige uma vantagem muito especial e até agora, na verdade, não analisada. Isto é, começámos com o povo que diz coisas. Decidimos que se refere a uma entidade ou propriedade e privilegiamos uma classe delas, as propriedades domésticas. Decidimos qual refere o povo; mas então, uma vez que o facto de se estar a referir a ela é efectivamente vão, dado que não tem nenhuma noção de estar a fazê-lo, encontrando-se antes inteiramente absorvido na vantagem especial que tem com a propriedade, temos de prosseguir tentando compreender essa perspectiva e as peculiaridades que pertencem à vantagem que é onde podíamos ter ficado desde o princípio, sem o périplo pela identidade. 
Considere, por exemplo, o projecto que consiste em defender o realismo moral através da descoberta de uma propriedade ou agregado de propriedades naturais com a qual se identifique a propriedade do bem. O problema residual é então o de dizer o que é ter uma vantagem moral sobre sejam quais forem as propriedades que forem seleccionadas. Em que consiste isso de vê-las sob a designação de $\mathrm{O}$ Bem? Tem qualquer coisa a ver com políticas, escolhas, atitudes, emoções. Por que motivo devem então estas coisas fixar, por si, a semântica do predicado, tal como nós, os expressivistas, o usamos? Que tipo de erro é cometido pelos que se recusam a encarar as propriedades domésticas identificadas sequer como co-extensivas com o bem? É um erro objectivo, um erro cognitivo ou um erro de atitude e estrutura volitiva mas, nesse caso, como podemos falar de erro? Não há resposta. A identidade oculta com uma propriedade natural não desempenha qualquer papel no pensamento ou prática populares; não precisa de ser por si reconhecida como o seu objecto favorito de referência; na verdade, a maior parte dos seus proponentes não poderia provavelmente perceber a sua identificação natural que, nesta filosofia, revela a sua essência. Não tem, portanto, privilégios semânticos.

Mas não nos dará a identidade qualquer coisa, importante para a metafísica, ainda que o não seja para compreender o conceito (ou trapalhada) popular? Domestica propriedades à maneira reducionista, deixando que a vantagem que colhemos delas seja suficientemente variável para que não se siga o reducionismo do significado. Mas por causa destas reticências sensatas, o lugar do conceito nas nossas vidas (e isso significa o lugar da predicação nas nossas vidas) não é tratado. Uma vez que, na minha perspectiva, as propriedades são as sombras semânticas dos predicados, alcança-se com isto muito pouco. Com suficiente latitude sobre a referência (e, se o que disse anteriormente estava certo, tal latitude é-nos imposta) não será difícil descobrir uma propriedade doméstica que sirva como a referência de um adágio popular, desde que seja o que for que interessa realmente ao povo (tal como a verdade dos juízos proferidos em termos semânticos ou morais, ou em termos de qualia) varie com a verdade de um complexo de juízos domésticos.

Poderia acrescentar como um codicilo que não tenho mais fé no outro modo principal de domesticar áreas difíceis — que consiste em investir numa equação «sensível à resposta». ${ }^{11}$ Uma discussão adequada de tais teorias

\footnotetext{
${ }^{11}$ A expressão é de Mark Johnston; veja-se o seu «Dispositional Theories of Value», Proceedings of the Aristotelian Society Supplementary Volume 63 (1989) pp. 139174. Veja-se também Philip Pettit, «Realism and Response Dependence», Mind 100
} 
conduzir-nos-ia para lá do âmbito deste ensaio, mas o erro comum a ambos é tornar a reacção a que damos voz quando moralizamos ou proferimos veredictos semânticos (ou juízos relativos a propriedades de segunda ordem) parte do tópico, como se olhássemos constantemente de lado, como se não nos ocupássemos da justiça, do significado ou do cheiro, mas da nossa própria disposição para descobrir a justiça, o significado ou um cheiro.

\section{IV}

Eis, pois, a morte da filosofia analítica. E, no entanto, o cadáver caminha. Talvez só sejamos bons a expor os erros de colegas suficientemente insensatos para transgredir as fronteiras determinadas na secção I. Sou chocantemente mais optimista que isso. Defendo que se deve responder «e depois?» ou manter tanta indiferença à crítica quanta a que conseguirmos. Estou, nada mais, nada menos, a recomendar a prática efectivamente existente dos filósofos analíticos, que tem consistido em prosseguir como se os fundamentos da sua abordagem fossem tão seguros como nos melhores dias pré-witttgensteinianos ou pré-quineanos. O meu objectivo é unicamente dar-lhes uma espécie de boa consciência. Não seremos expulsos do Paraíso, mas será bom ter qualquer coisa que certifique o nosso direito a habitá-lo.

A verdadeira situação é visível se voltarmos a olhar para as páginas que acabei de escrever, ou para páginas mais eloquentes e detalhadas de autores como Putnam e Rorty. Devemos ficar surpreendidos ao verificar que, no próprio curso da sua exortação a favor da morte da filosofia analítica, eles estão, na verdade, a fazer filosofia analítica. Podem estar a fazê-lo de forma um tanto impressionista, mas isso pode e deve ser alterado. Além disso, este tipo de inconsistência pragmática parece inevitável. O que tem de ser defendido é que, por exemplo, não existe nenhum a priori, ou nenhuma epistemologia normativa, ou nenhuma redução de um discurso a outro, ou nenhuma identificação de propriedades de um nível com as de outro. Não há maneira de comprar a verdade ou falsidade de tais teses excepto através das maneiras em que estamos treinados: desdobrando os argumentos, distinções e técnicas que preencheram revistas como a Philosophical Review, a Mind ou a Canadian Journal of Philosophy no último século, mais ou menos, e que já eram visíveis em Aristóteles e em Descartes desde muito antes. Não há maneira de compreender completamente que o problema da mente-corpo está deformado e mal colocado, se é que realmente o está, excepto traba-

(1991) e, para um tratamento excelente, veja-se os estudos em Response Dependent Concepts, Peter Menzies, org. (Canberra: Research School of Social Sciences, 1991). 
lhando em prol de uma concepção melhor de mente e corpo na qual o problema não se levante - e esta é precisamente a ocupação, em grande medida, da filosofia da mente analítica contemporânea.

Esta afirmação tem sido contrariada, sobretudo por Richard Rorty. Ao perceber que seremos sugados para o remoinho analítico se tentarmos defender que os problemas tradicionais da filosofia estão mal colocados, ou que serão bem abordados de outro modo qualquer, Rorty aconselha-nos a mudar de assunto ou a troçar de tudo isso. Na verdade, no que me parece um erro monumental de identificação de tom literário, Rorty descreve as lutas atormentadas das Investigações Filosóficas como um exemplo da última atitude, como se Wittgenstein se tivesse sentido à vontade divertindo-se em Paris. ${ }^{12}$ Mas, na verdade, nenhuma das recomendações é muito apelativa. Uma coisa é acreditar que o problema da mente-corpo ou que o problema da linguagem-mundo tal como o herdámos do passado está deformado, mal colocado e precisa de ser afastado. Uma coisa muito diferente é dizer que essas enfermidades são suficientes para delimitar uma área proibida; que devemos literalmente ser proibidos de cultivar qualquer pensamento sobre o ser humano ou sobre o significado, ainda que unicamente para compreender como evitar as ciladas nas quais os nossos predecessores caíram, segundo nos dizem. Ao voltar as costas não alcançamos uma perspectiva melhor; ficamos sem nenhuma perspectiva. Analogamente, uma coisa é troçar desses predecessores, como na verdade todos gostamos de fazer; mas saber que isso é mais do que uma rebeldia adolescente é outra coisa. Saber que temos o direito de troçar implica ter uma perspectiva melhor da área. Ter uma perspectiva melhor pode muito bem significar que achamos que a área não contém alguns temas, tal como foram colocados, nem algumas balizas, previamente admitidas como pontos fixos. À partida nada se exclui, excepto, como digo, a crença de que não ter nenhuma perspectiva é ter uma perspectiva melhor. $\mathrm{E}$ ter uma perspectiva qualquer significa navegar ao encontro do redemoinho analítico.

É claro que a questão não pode ser deixada nestes termos. Se as enfermidades da filosofia analítica são tão visíveis, por que razão é ela uma prática inevitável caso queiramos ter uma compreensão das noções mais gerais de acordo com as quais pensamos sobre as coisas? A minha resposta é que todas as teses enumeradas anteriormente são funcionalmente falsas. No nosso pensamento é como se existisse um a priori, uma filosofia primeira, guardiã das normas, uma perspectiva distanciada ou lateral sobre muitas das nossas

\footnotetext{
12 Richard Rorty, «Keeping Philosophy Pure», in Consequences of Pragmatism (Minneapolis, MN: University of Minnesota Press, 1982), pp. 34.
} 
práticas, ontologia, filosofia da mente e até ética prática e teoria política. Não só funcionamos como se estas coisas fossem verdadeiras, como não se consegue ver qualquer alternativa a essa prática. Talvez o a priori funcional possa ser diagnosticado como a pressuposição absoluta do pensamento de uma época, despojando-o do seu charme kantiano ao mesmo tempo que nos dá o direito de prosseguir nos seus termos, acontecendo o mesmo com as outras categorias da crítica.

Penso que a verdadeira situação é muito semelhante à da crítica literária. Depois da primeira exposição completa a Kuhn e a Feyerabend, muitos teóricos pensaram que a prática da avaliação tinha sido desmascarada. O juízo tinha sido exposto como um disfarce de interesses de classe ou de qualquer outro preconceito que na altura estivesse a ser ridicularizado, e a sua prática foi abolida a favor de um levantamento antropológico dos modos segundo os quais tinha sido sempre levado a cabo. ${ }^{13}$ Mas, depois de alguma reflexão, começou-se a perguntar se a coisa se ficava por aqui. Dado ser inevitável que algumas pessoas preferem uns livros a outros, a atitude de afastar a possibilidade de uma discussão mais ou menos inteligente dessas preferências parece despótica; admitindo que os padrões que trazemos para tais discussões têm raízes e são contingentes, históricos, etc., eles são, no entanto, nossos - e se queremos conduzir uma discussão inteligente, temos de os usar. ${ }^{14}$ Podemos, com certeza, acrescentar um P.S. no final, afirmando que os juízos emitidos são nossos, aqui e agora. Mas o P.S. não funciona como um tipo de qualificação, dado que se for acrescentado em qualquer lado, deve ser acrescentado em todo o lado. Uma vez que deveria aparecer no final de todas as frases, teria de acabar por precisar de ser abreviado num nada. O juízo crítico ergue-se então, qual Fénix, das suas próprias cinzas.

Analogamente - sugiro - os projectos de ver o que se segue do quê (a demonstração ou o a priori), o que conta como virtude ou vício epistemológico (a normatividade), que relações de sobreveniência, causalidade e mereologia podemos estabelecer entre entidades de diferentes tipos de discurso (a ontologia), tal como a filosofia da mente e o raciocínio prático, não são silenciados. São no máximo transpostos para um tom ligeiramente diferente pelas considerações que foram apresentadas contra eles. Voltar as costas não é a única alternativa à nossa disposição ao pensamento cuidado sobre as

\footnotetext{
${ }^{13}$ Esta é uma das mensagens de Barbara Herrnstein Smith, Contingencies of Value (Cambridge, MA: Harvard University Press, 1988).

${ }^{14}$ Este é um aspecto sublinhado por Stanley Fish em muitos ensaios; por exemplo, «Consequences» in Doing What Comes Naturally (Durham: Duke University Press, 1989).
} 
nossas categorias, mais do que o é em axiologia. E não se trata de não haver trabalho para fazer (considere-se só a quarta afirmação na crítica da secção I, a afirmação imensamente popular de que deveríamos contentar-nos com uma pluralidade de discursos, com as suas diferentes perspectivas do mundo, e reflicta-se de seguida sobre a questão de saber por que razão uma única realidade reconcilia diferentes perspectivas no caso espacial, e, sendo assim, como poderá ela fazê-lo em termos mais gerais). ${ }^{15}$

Os leitores poderão sentir que as minhas ideias revelam uma abordagem «quase-realista» às normas da discussão filosófica, estando para uma primeira filosofia à maneira antiga como uma abordagem quase-realista da ética está para um racionalismo kantiano à maneira antiga ou para um realismo reducionista. Não é fácil sentirmo-nos confortáveis com a autoconfiança resultante, mas melhora-se com a prática. $\mathrm{O}$ verdadeiro problema, segundo me parece, não resulta tanto de as considerações da secção I eliminarem os assuntos, mas do facto de tornarem genuinamente mais difícil ver que método bem sucedido poderá haver. As censuras que lancei contra os métodos da ciência de Oxford, contra o equilíbrio reflexivo e contra abordagens modernas populares da metafísica, por exemplo, não perdem a sua força só porque se praticam esses métodos. Talvez, como Klimt pensava, estejamos condenados a encenar uma tragédia perpétua: a reflexão filosófica tem de ser praticada; logo, pratica-se; logo, pode praticar-se. Mas, excepto em poucos casos, a sua prática não é bem sucedida; pelo menos não o é se houver um objectivo exterior a si própria.

(Tradução de Desidério Murcho)

Simon Blackburn

Dept. of Philosophy

University of North Carolina at Chapel Hill

Chapel Hill, NC 27599 USA

Simon_Blackburn@unc.edu

\footnotetext{
${ }^{15}$ Esta enigmática instrução é cumprida no meu ensaio «Enchanting Views», publicado nas actas da conferência de St. Andrews de 1990 em honra de Hilary Putnam.
} 